\title{
La diferencia entre nacionales y residentes en el impuesto sobre la renta: análisis de una reforma inacabada a partir de un caso práctico desde la Ley 1607 de 2012
}

\section{The difference between nationals and residents in the income tax: Analysis of an inaccurate reform from a practical case from Law 1607/2012}

\author{
Luis Alberto Carmona Movilla ${ }^{1}$
}

\section{Resumen}

A partir de la reforma tributaria Ley 1607 de 2012, el Estado colombiano reformó el sistema tributario de las personas naturales y se realizó una separación entre los nacionales y extranjeros, y residentes y no residentes. Sin embargo, los cambios no se implementaron en todo el Estatuto Tributario (ET), lo que ocasionó problemas jurídicos a los nacionales colombianos no residentes que vienen a trabajar a su país de origen, los cuales corresponde analizar en el presente escrito.
En este sentido, para llevar a cabo el análisis planteado, es necesario abordar de manera crítica las siguientes situaciones: la obligación formal de declarar, las retenciones en la fuente, la ley de trabajador migratorio, los convenios para evitar la doble imposición y la forma de depurar la renta de los no residentes. Además de los resultados del análisis, se plantea una propuesta para solucionar estas situaciones.

Ahora bien, el presente artículo aborda la problemática en cuestión antes de la reforma tributaria de 2012 (Ley 1607), después de la 
misma y luego de las modificaciones de la Ley 1819 de 2016, por medio del análisis de caso.

Palabras clave: Reforma tributaria Ley 1607 de 2012, Colombianos no residentes, Sistemas de declaración, Retención en la fuente, Trabajador migratorio.

\section{Abstract}

Given the tax reform Law 1607 of 2012, the Colombian government initiates a turn to the tax systems of natural person, changing the distinction between nationals and foreigners, to a structured for residents and nonresidents one. However, the changes were not implemented throughout the Tax Statute (TS), which caused serious legal problems for non-resident Colombians who came to work in Colombia. The following research was developed under the methodology of the case study, with the mean goal of analyzing the discriminatory acts that the tax rule generates in non-resident Colombians against foreigners; specifically, the formal obligation to declare, the withholding tax, the migrant worker's law, the agreements to avoid double taxation, and the way to purge the nonresidents income. In addition to the results of the analysis, a law project is propused to eliminate the word "foreigner" in some ST articles, in order to solve the discriminatory acts and the legal gaps in the law, referring to non-resident Colombians.

Keywords: Tax reform Law 1607 of 2012, Non-resident Colombians, Filing systems, Withholding tax, Migrant worker.

\section{Introducción}

Cuando se habla de "no residentes" en materia tributaria, se podría entender que solo se hace referencia a los de nacionalidad extranjera. Esto dejaría a los colombianos no residentes con serios problemas jurídicos al momento de definir, por ejemplo, la obligación formal de declarar la tarifa del impuesto a la renta, la tarifa de retención en la fuente y los beneficios de trabajadores migrantes, entre otros.

Antes de la reforma tributaria de 2012 (Ley 1607), la tributación en Colombia estaba diseñada para diferenciar, por un lado, el régimen tributario de los nacionales y, por el otro, el de los extranjeros. Con los cambios normativos de dicha época (2012) se hace una distinción entre el régimen de los residentes y el de los no residentes. Pero, desafortunadamente, este objetivo no se configuró de la mejor manera en el Estatuto Tributario (en adelante ET), lo cual trajo como resultado los problemas jurídicos que se abordarán en este trabajo. Se observa también que el Ministerio de Hacienda y Crédito Público (en adelante MHCP), hasta el año gravable 2016, en sus decretos para determinar a los no obligados a declarar por cada año gravable, ha hecho de manera errónea una fusión entre la clasificación que tenía el $\mathrm{ET}^{2}$ y la que introdujo la reforma tributaria Ley 1607 de 2012 en su Artículo 10, la cual modificó el Artículo 329 del ET, así:

- Empleado y

- trabajador por cuenta propia.

${ }^{2}$ Otras personas naturales (Artículo 592); asalariados (Artículo 593); trabajadores independientes (Artículo 594-1) y los topes generales del Artículo 594-3; 
Ello trajo como resultado una nueva clasificación para determinar a los no declarantes, la cual se pudo evidenciar en el Artículo 3 del Decreto 2105 de 2016, emitido por el MHCP, así:

- Literal a) Empleados

- Literal b) Los trabajadores por cuenta propia

- Literal c) Las demás personas naturales y asimiladas a estas

- Literal d) Personas naturales o jurídicas extranjeras

A su vez, esta categorización generó los siguientes inconvenientes:

- Tratar como declarantes por una norma y no declarantes por otra norma a personas que tienen las mismas características;

- violación del principio de seguridad jurídica para las personas naturales colombianas o extranjeras no residentes.

Por lo anterior, se generaría una incertidumbre jurídica a los nacionales sin residencia con ingresos y patrimonio inferiores a 1.400 UVT y 4.500 UVT, respectivamente. Esto en el sentido de que, por un lado, el MHCP, mediante la emisión de sus decretos para determinar a los no declarantes por cada año gravable (para el año 2016 fue el Decreto 2105) los obliga a declarar renta; y, por otro lado, el ET, en sus Artículos 592, 593 y 594-1, los clasifica como no declarantes. En consecuencia, habría que plantearse la pregunta de por qué el Decreto 2105 de 2016 va en contra de lo señalado en la ley, específicamente en los Artículos 592, 593 y 594-1 del ET.
Finalmente, para abordar la problemática planteada se realiza un estudio de caso, en donde se describen las características tributarias del sujeto objeto de estudio al cual se le hace un análisis de su obligación formal de declarar, de las retenciones en la fuente que lo afectan, se analiza la ley de trabajador migratorio, se describe su sistema tributario y se hace una mirada por los convenios para evitar la doble imposición. Las conclusiones se van desarrollando en cada capítulo señalado, las cuales adoptan el nombre de "problema jurídico".

\section{Recuento de los hechos}

El caso de estudio en este trabajo de investigación se ubicó en una universidad (en adelante, Fundación) de la ciudad de Cartagena, en el Caribe colombiano. En dicha institución, se observó a un grupo de trabajadores (en adelante, Docente) que poseían unas características específicas, las cuales permitieron determinar un vacío jurídico en las normas tributarias, el cual constituyó el objeto de la presente indagación.

El docente es una persona natural, de nacionalidad colombiana, quien desde el año 2010 se fue a otro país (Venezuela, con el cual no existe CDI vigente) a trabajar en una universidad. Sin embargo, todos los años, a partir de 2011, regresó a Colombia para cumplir compromisos de tipo académico con la Fundación, en los periodos de junio a agosto y de noviembre a diciembre. Para tal efecto, suscribió un contrato laboral de acuerdo con las normas vigentes en Colombia, con las siguientes características:

Contrato de medio tiempo, el cual inicia el 15 de junio hasta el 15 de agosto, y empieza 
nuevamente el 15 de noviembre hasta el 15 de diciembre, de 4 horas diarias o 24 semanales, con un sueldo mensual de $\$ 2.100 .000$ más las prestaciones legales. Teniendo en cuenta la información anterior -y el Artículo 10 del ET-, el docente es considerado en Colombia como un no residente para efectos tributarios.

La implicación que el factor de ser no residente trae a su declaración de renta sería estar sujeto al impuesto solo por las rentas de fuente nacional y por su patrimonio poseído en el país, de acuerdo con el Artículo 9 del ET, inciso 2.

\section{Obligación formal de declarar}

\section{A. Antes de la reforma tributaria Ley}

\section{7 de 2012}

Cuando se analiza el Artículo 593 del ET, el docente se clasifica en la categoría tributaria de asalariado, por las siguientes razones:

$\checkmark$ Como los efectos que produjo la no residencia colombiana de declarar solo las rentas de fuente nacional, el docente solo tendrá que declarar los ingresos por el contrato laboral suscrito en la Fundación, debido a que esos son los únicos ingresos que desde el año 2011 obtiene en Colombia. Por lo tanto, el $100 \%$ de sus ingresos son producto de una relación laboral legal y reglamentaria, la cual supera el $80 \%$ que consagra el inciso 1 del Artículo 593 del ET.

$\checkmark \mathrm{Su}$ patrimonio bruto no excede las 4.500 UVT en el año.

$\checkmark$ No es responsable del impuesto sobre las ventas.

$\checkmark$ Sus ingresos no superan los 1.400 UVT en el año (ver tabla 1).
Tabla 1. Ingresos obtenidos por el docente en Colombia año 2016

\begin{tabular}{|l|r|}
\hline Salarios & $\$ 6.300 .000$ \\
\hline Cesantías & $\$ 1.575 .000$ \\
\hline Intereses de cesantías & $\$ 47.000$ \\
\hline Prima de servicios & $\$ 1.575 .000$ \\
\hline Vacaciones & $\$ 788.000$ \\
\hline Total ingresos & $\$ 10.285 .000$ \\
\hline
\end{tabular}

Fuente: Elaboración propia.

Teniendo en cuenta lo anterior, por cumplir con todos los requisitos y topes establecidos en los Artículos 593 y 594-3 del ET, el docente sería un asalariado no obligado a declarar renta por cada uno de los años gravables que conserve esas mismas condiciones laborales.

\section{B. Después de la reforma tributaria Ley 1607 de 2012}

A partir del año gravable 2012, cuando entra en vigencia la Ley 1607, el MHCP emite todos los años un decreto que determina los plazos para declarar, los formularios que se deben usar para tal fin y otros aspectos. En consecuencia, desde el año 2013, el MHCP promulgó decretos que establecieron las condiciones para no ser declarantes de renta. Sin embargo, utilizó una nueva clasificación de personas naturales, la cual resulta de fusionar dos regulaciones distintas de personas naturales, a saber:

- Las personas naturales y los topes de ingreso y patrimonio estipulados en los Artículos 592 a 594-1 (obligación formal);

- las condiciones establecidas en el Artículo 594-3 del ET (obligación formal), y 
- las personas naturales contempladas en el Artículo 329 del ET, incorporada por la Ley 1607 de 2012 en su Artículo 10 (obligación sustancial).

Por consiguiente, para el año gravable 2016, el MHCP expidió el decreto 2105 del 22 de diciembre del mismo año, y en su Artículo 3 decretó los contribuyentes no obligados a presentar declaración de impuesto sobre la renta y complementario. Asimismo, modificó el DUT Ley 1625 de 2016, en el Artículo 1.6.1.13.2.7, y estableció una clasificación de personas naturales no declarantes, así:

1)Empleados;

2) los trabajadores por cuenta propia;

3) las demás personas naturales y asimiladas a estas;

4) personas naturales o jurídicas extranjeras.

Así las cosas, el docente colombiano no residente se clasificaría en la categoría tributaria de declarante de renta, solo por carecer de la residencia colombiana. Esto se debe a que no configura ninguno de los supuestos estipulados por las reglamentaciones que emite el MHCP.

\section{Después de la reforma tributaria Ley 1819 de 2016}

El ambiente que generó la reforma tributaria Ley 1819 de 2016, en cuanto a la obligación formal de declarar de las personas naturales, deberá girar nuevamente alrededor de los Artículos 592, 593 y 594-3. Cabe resaltar que el Artículo 594-1, sobre los trabajadores independientes, fue derogado. En este orden de ideas, para determinar la obligación formal de declarar, habrá que recurrir a las condiciones establecidas en los artículos anteriormente expuestos. Es decir, que la obligación formal de declarar se determinará como se indica en este capítulo (en el punto A), cuando nos referimos a la obligación formal de declarar de acuerdo con la normatividad vigente hasta antes de la reforma tributaria Ley 1607 de 2012.

Dado que la reforma Ley 1819 de 2016 derogó las categorías de empleado y trabajador por cuenta propia, entonces, dejaría sin piso jurídico los decretos que el MHCP emite todos los años, donde este define los no obligados a declarar, y para tal efecto utiliza las categorías del Artículo 329 del ET.

\section{Problema jurídico}

Ahora bien, si se toma nuevamente a la persona del caso planteado (el docente), el cual se acaba de examinar a la luz de los Artículos 593 y 594-3 del ET, y en consecuencia se clasificó en la categoría de nacional no residente y asalariado no obligado a declarar. Por otro lado, se analiza frente a cada uno de los literales del Decreto 2105 de 2015 en su Artículo 3, el cual modifica el Artículo 1.6.1.13.2.7 del DUR 1625 de 2016, donde se definen los no obligados a declarar por parte del MHCP, y se encuentra lo siguiente:

Literal a) Empleados: el docente no puede pertenecer a esta categoría por no ser residente.

Literal b) Los trabajadores por cuenta propia: el docente tampoco puede pertenecer a esta categoría por no ser residente.

Literal c) Las demás personas naturales y asimiladas a estas: el docente tampoco puede pertenecer a esta categoría, porque 
en el mismo literal dice que tiene que ser residente.

Literal d) Personas naturales o jurídicas extranjeras: el docente, por tener la nacionalidad colombiana, no puede pertenecer a esta categoría, porque a esta pertenecen los extranjeros. Teniendo en cuenta que este literal va en armonía con el Artículo 592 numeral 2 del ET, al cual se hizo un análisis, y la interpretación gramatical arroja que su aplicación es para los extranjeros, sean personas naturales o jurídicas.

Por lo tanto, según el MHCP, el docente es un declarante del impuesto de renta y complementarios por el año gravable 2016, por el simple hecho de no ser residente; situación generada por no poder pertenecer a ninguna de las categorías de no declarantes definidas en cada uno de sus literales antes expuestos del Artículo 3 del decreto 2105 de 2016. Pero si se analiza a la luz de los Artículos 593 y 594-3 del ET, es un no declarante del impuesto sobre la renta. Esto trae como consecuencia que dos normas entren en lo que podría llamarse una antinomia.

Teniendo en cuenta lo anterior, vale recordar que el ET es un decreto ley. En consecuencia, el Decreto 2105 de 2016 emitido por el MHCP, según el orden jerárquico de las normas, no puede regular algo que esté en contra de lo contemplado en el ET. Por consiguiente, se podría resolver la antinomia con el principio de la prevalencia de ley superior, contemplado en el Artículo 189 numeral 11 de la Constitución Política. Pero el asunto no se resuelve tan fácilmente, debido a que los decretos del Ministerio gozan del principio de legalidad, y mientras estén vigentes se deben cumplir. La única solución posible es solicitar la nulidad de dicho decreto, de acuerdo con lo estipulado en el Artículo 237 de la Constitución.

\section{Retenciones en la fuente}

En el tema de retención en la fuente también se observaron problemas jurídicos que afectan a los colombianos no residentes. A continuación, se presentan las conclusiones obtenidas luego de plantear dos escenarios: antes y después de la reforma tributaria Ley 1819 de 2016.

\section{A. Retención en la fuente docente extranjero}

\section{Antes de la reforma tributaria Ley 1819 de 2016}

De acuerdo con las características del sujeto objeto de estudio en esta investigación, denominado el docente, ¿se podría aplicar lo estipulado en el Artículo 409 del ET? En seguida se analiza esta situación:

Artículo 409. Tarifa especial para profesores extranjeros. En el caso de profesores extranjeros sin residencia en el país, contratados por períodos no superiores a cuatro (4) meses por instituciones de educación superior, aprobadas por el ICFES, únicamente se causará impuesto sobre la renta a la tarifa del siete por ciento (7\%). Este impuesto será retenido en la fuente en el momento del pago o abono en cuenta.

$\mathrm{Al}$ analizar el artículo anterior, se observa que el tipo de contrato mencionado es para labores ejecutadas en universidades colombianas y por profesores que tengan la calidad de extranjeros. Ello implica discriminar a los docentes colombianos que no sean residentes fiscales en Colombia, debido a que no 
pueden gozar de la tarifa del $7 \%$ contemplada en el Artículo 409 del ET.

\section{Después de la reforma tributaria Ley 1819 de 2016}

Aunque se piense por parte de la DIAN que la palabra extranjero fue eliminada tácitamente de los Artículos 592 numeral 2 y 408 numerales 2 y 3 , se observa que la reforma tributaria Ley 1819 de 2016 mantuvo la figura de profesor extranjero sin residencia y, por consiguiente, su tarifa especial de retención en la fuente del $7 \%$ consagrada en el Artículo 409 del ET. Sin embargo, no hay que perder de vista que este docente es contratado bajo una relación laboral y legal colombiana, hecho este que lo convierte en un asalariado. Por consiguiente, se debe tener presente que la modificación que el Artículo 17 de la Ley 1819 de 2016 hace al Artículo 383 del ET es, precisamente, eliminar la figura de empleado de dicha retención; lo que trae como consecuencia que esa retención se le pueda aplicar a todo aquel que obtenga una renta laboral consagrada en el Artículo 103 del ET, sin importar la nacionalidad ni la residencia. Por lo tanto, al profesor extranjero también se le puede aplicar y descontar la retención contemplada en el Artículo 383 del Estatuto. En los marcos de las observaciones anteriores, se podría concluir que se está frente a una antinomia; es decir, dos normas: los Artículos 409 y 383 del ET, que regulan de manera diferente una misma situación fáctica.

\section{Problema jurídico}

La antinomia señalada en el párrafo anterior (referente al docente extranjero sin residencia) parece difícil de resolver, debido a que confluyen al mismo tiempo dos principios en contraposición. Por un lado, se resolvería la antinomia si se aplicase la retención del Artículo 409 del ET, acudiendo a la regla de la prevalencia de ley especial sobre la general, consagrada en el Artículo 5 de la Ley 57 de 1887; y de otro modo, también se podría aplicar la retención del Artículo 383 del ET (modificada por la Ley 1819 de 2016), si se acudiese a la regla de ley posterior, contemplada en el Artículo 2 de la Ley 157 de 1887.

Por otro lado, antes de la reforma tributaria Ley 1819 de 2016, en los Artículos 409 (tarifa de retención en la fuente) y el parágrafo del Artículo 247 (tarifa del impuesto de renta) del ET, se guardaba coherencia con el tema del tiempo de contratación para el profesor extranjero, al señalar cuatro (4) meses.

Sin embargo, la reforma tributaria Ley 1819 de 2015, con el Artículo 10, modifica el periodo de contratación del docente extranjero consagrado en el parágrafo del Artículo 247 del ET, al pasar de cuatro (4) meses a 182 días. Pero no se modifica el tiempo de contratación de cuatro meses para la retención en la fuente del docente extranjero, consagrado en el Artículo 409 del ET, lo cual trae como consecuencia que el tiempo de contratación de 4 meses para la retención del Artículo 409 del ET quede diferente al contemplado en el parágrafo del Artículo 247, el cual se refiere a un tiempo de contratación de 182 días para aplicar la tarifa del $7 \%$ en el impuesto de renta de los docentes extranjeros.

Lo anterior refleja un descuido por parte del Legislador, el cual implica que si el docente extranjero tiene un contrato mayor a cuatro (4) meses y menor a 182 días traería como consecuencia lo siguiente: le aplicaría la tarifa del $7 \%$ en el impuesto de renta 
consagrado en el parágrafo del Artículo 247, pero por superar los 4 meses de contratación, no le aplicaría la tarifa de retención del 7\% consagrado en el Artículo 409 del ET, lo que implicaría una tarifa del impuesto diferente al de la retención.

Por último, si al profesor extranjero no residente, por principio de norma especial, le aplicasen la retención en la fuente del Artículo 409 del ET, según el Artículo 592 numeral 2 del Estatuto, no estaría obligado a declarar; por lo tanto, la retención del $7 \%$ sería su impuesto. Esto generaría una situación de inequidad con los profesores colombianos no residentes, quienes tendrían que declarar y soportar una tarifa de retención en la fuente del $15 \%$ y del $35 \%$ en la declaración del impuesto de renta.

Por último, antes de la reforma tributaria Ley 1819 de 2016 hay que tener en cuenta que el docente colombiano no residente tiene un contrato laboral firmado en Colombia; por lo tanto, el Decreto 099 de 2013 contempla la posibilidad de aplicar la retención en la fuente del Artículo 383 del ET a todas aquellas personas naturales que no clasifican en la categoría de empleado, pero que tienen una relación laboral. Entonces, por el principio de legalidad, llevaría a la retención del Artículo 383 del ET y, como consecuencia de esto, la obligación de declarar debido a que no puede cumplir con los condicionamientos del numeral 2 del Artículo 592 del ET.

\section{B. Retención en la fuente contrato laboral diferente a docente}

Para determinar otros problemas jurídicos de los colombianos no residentes, también se analizaron contratos laborales diferentes a docentes, a pesar de que el sujeto objeto de estudio tenía contrato laboral como profesor en una Universidad colombiana. Por lo tanto, en esta retención, se analizó como a un colombiano asalariado no residente.

\section{Retención en la fuente desde la} interpretación gramatical de la ley

Antes de la reforma tributaria Ley 1819 de 2016. Si se toman como referentes el Artículo 27 del Código Civil Colombiano y los fundamentos teóricos de esta investigación, a saber: a) la importancia de la interpretación gramatical para el ordenamiento jurídico, y b) la injustificada interpretación de la modificación tácita que hace la DIAN de la palabra extranjero en los Artículos 406 y 592 del ET, se determinarían los siguientes problemas jurídicos:

Si se analiza el Artículo 406 del ET, que trata sobre retenciones por pagos al exterior, así:

\section{ARTÍCULO 406. CASOS EN QUE DEBE} EFECTUARSE LA RETENCIÓN. Deberán retener a título de impuesto sobre la renta, quienes hagan pagos o abonos en cuenta por concepto de rentas sujetas a impuesto en Colombia, a favor de:

1. Sociedades u otras entidades extranjeras sin domicilio en el país.

2. Personas naturales extranjeras sin residencia en Colombia.

3. Sucesiones ilíquidas de extranjeros que no eran residentes en Colombia.

Como se observa en el anterior artículo, este tipo de retención no les aplica a los colombianos no residentes, por el simple hecho de no tener la calidad de extranjeros. 
De acuerdo con lo expresado en el párrafo anterior, a este colombiano no residente, si no se le puede aplicar la retención por pago al exterior contemplada en el inciso primero del Artículo 408 del ET; entonces, por ser un asalariado, se analizará la posibilidad de aplicar la retención contemplada en el Artículo 383 del Estatuto, el cual trata sobre retención en la fuente por pagos laborales a las personas naturales pertenecientes a la categoría de empleado.

Por consiguiente, como se trata de un colombiano no residente, este no podrá pertenecer a la categoría de empleado y, por lo tanto, no se le podrá aplicar la retención del Artículo 383 del ET. De acuerdo con lo expuesto en este párrafo, el colombiano asalariado sin residencia, antes de la reforma Ley 1819 de 2016, no tendría concepto de retención en la fuente, es decir, el contratante de un colombiano asalariado no residente quedaría sin poderle determinar qué tipo de retención en la fuente aplicar. Más adelante se analizarán los efectos que el principio de legalidad del parágrafo 1 del Artículo 1 del Decreto 099 del 25 de enero de 2013 produce sobre este caso.

Después de la reforma tributaria Ley 1819 de 2016. Por consiguiente, se debe tener presente que la modificación que el Artículo 17 de la Ley 1819 de 2016 hace al Artículo 383 del ET es precisamente eliminar la figura de empleado de dicha retención. Esto trae como consecuencia que esa retención se le pueda aplicar a todo aquel que obtenga una renta laboral consagrada en el Artículo 103 del ET, sin importar la nacionalidad ni la residencia; por lo tanto, al asalariado extranjero no residente se le puede aplicar y descontar la retención contemplada en el Artículo 383 del ET, por percibir una renta de trabajo. Y al mismo tiempo, acudiendo a la regla de ley especial, también se le puede aplicar la retención en la fuente por pagos al exterior, contemplada en el inciso primero del Artículo 408 del ET, por ser un pago a un no residente. Todo lo anterior generaría una antinomia entre lo contemplado por el Artículo 383 del ET y el inciso primero del Artículo 408 del mismo estatuto.

Por otra parte, como al asalariado extranjero sin residencia le apliquen las retenciones de los Artículos 407 al 411, dado que cumple con las condiciones contempladas en el Artículo 592 numeral 2, ganaría el beneficio de no declarar renta. En cambio, los asalariados no residentes pero que sean colombianos, no estarían gozando del beneficio de no declarar, en el entendido de que por no ser extranjeros, a estos no se les puede aplicar la retención de los Artículos 407 al 411 y, por lo tanto, no cumplen con las condiciones del Artículo 592 numeral 2 del ET.

El problema jurídico es el siguiente: la antinomia generada para los asalariados extranjeros no residentes después de la reforma tributaria Ley 1819 de 2016, entre el renovado Artículo 383 del ET (modificado por la Ley 1819 de 2016) y el inciso primero del Artículo 408 del mismo estatuto, no es tan fácil de resolver debido a que estarían dos reglas en contraposición. Se trata de la regla de ley especial, que permite la retención del Artículo 408 del ET, por ser un pago a un no residente, contra el principio de ley posterior, que permite la retención del Artículo 383 del ET, por ser una renta de trabajo. 
La problemática anterior también quedó plasmada en el análisis que hicieron Victoria Hoyos y Camilo Rodríguez, en obra publicada por el Externado de Colombia, sobre retención en la fuente sobre pagos laborales, el cual se comparte a continuación:

Frente a este interrogante se presentan dos alternativas: i. que no exista tarifa de retención para un no residente colombiano que reciba ingresos laborales, dado el contenido de los Artículos 383 y 384 del ET y el Artículo 1 del decreto 099 de 2013, en el sentido de dirigir sus prescripciones únicamente a residentes colombianos (Hoyos Londoño \& Rodríguez Peña, 2015).

El Decreto 099 de 2013 no se tuvo en cuenta para el análisis de este problema jurídico, debido a que esta problemática es producto de la interpretación literal de las normas. Sin embargo, la razón fundamental para no tenerlo presente es la siguiente: el parágrafo 1 del Artículo 1 del mencionado decreto ordena aplicar la retención del Artículo 383 a aquellas personas naturales que no son empleados pero que sí son asalariados. Por lo tanto, se considera que el decreto está sobrepasando el tenor literal de la ley, en el sentido de que el Artículo 383 está diseñado para retención de empleados. Se entiende que, por presunción de legalidad, hay que aplicar lo contemplado en el Decreto 099 de 2013, hasta tanto este no sea declarado nulo.

Contrariamente a lo que se ha expresado, cuando la reforma tributaria Ley 1819 de 2016 modifica el Artículo 383 del ET, se resuelve el problema de no tener concepto de retención para el colombiano asalariado no residente, debido a que se le puede aplicar la retención contemplada en el Artículo 383 del mismo estatuto. Pero se genera una antinomia con lo contemplado en el Artículo 408 inciso 1 acudiendo a la regla de ley especial.

Con respecto a la retención en la fuente para ingresos laborales, contemplada en el Artículo 383 del ET, es importante hacer el siguiente análisis:

El Artículo 388 del ET hace referencia a la depuración de la base gravable a fin de calcular la retención en la fuente, para lo cual hace una remisión de dicho cálculo a las rentas de trabajo; es decir, que tal depuración pueden desarrollarla las personas naturales que perciban dichas rentas. No obstante, para tal efecto se halla el siguiente problema: al analizar el ET existen dos tipos distintos de rentas de trabajo.

Con el fin de ilustrar lo afirmado anteriormente, a continuación se explicarán las dos clases de renta:

$\checkmark$ Rentas de trabajo del Artículo 103 del ET: a este tipo de rentas pertenecen los ingresos percibidos a través de las siguientes actividades: todas aquellas vinculadas a una relación laboral, los honorarios y servicios, sin hacer precisión de si estos sean percibidos por personas naturales residentes y no residentes, ni mucho menos de las personas relacionadas con la prestación del servicio ni de los días de contratación.

$\checkmark$ Rentas de trabajo del Artículo 335 del ET: a este tipo de rentas pertenecen las mismas estipuladas en el Artículo 103 del ET, pero excluyendo los honorarios prestados por dos o más personas con- 
tratadas por más de 90 días. Además, en este tipo de rentas sí hacen precisión sobre la persona que la percibe, en el sentido de que esta debe ser residente.

En el orden de las ideas anteriores, se presenta el siguiente problema: ¿a cuál de los dos tipos de rentas de trabajo se refiere el Artículo 388 del ET?

\section{Retención en la fuente desde la línea doctrinal de la DIAN}

Antes de la reforma tributaria Ley 1819 de 2016. En este apartado, se dará crédito a los argumentos que llevaron a entender eliminada tácitamente la palabra extranjero en los Artículos 406, 409 y 592 del ET, con el objetivo de analizar las consecuencias que se generan, a pesar de que los fundamentos teóricos de este estudio desvirtúan tal derogatoria. También se tendrá en cuenta lo contemplado en el parágrafo 1 del Artículo 1 del Decreto 099 de 2013, emitido por el MHCP. No obstante, hay que aclarar que en este trabajo de investigación se considera que dicho decreto sobrepasa lo contemplado en el Artículo 383 del ET sobre retención a empleados.

Para analizar la línea doctrinal que la DIAN ha venido construyendo en el tema de retenciones por pago al exterior, se tendrían que observar las siguientes normas: Concepto DIAN 24300 de 2015, Oficio DIAN 016385 de 2015 y la Ley 1607 de 2012. Para la DIAN, la palabra extranjero se entiende eliminada tácitamente de los numerales 2 y 3 del Artículo 406 y numeral 2 del Artículo 592 del ET. Todo lo anterior debido a que la Ley 1607 , en su Artículo 9, modifica el Artículo 247 del ET, eliminando la condición de extranjero en las personas naturales no residentes, y de esta forma aplica la tarifa del impuesto de la renta al 33\%. En consecuencia con lo anterior, a los colombianos no residentes evidentemente se les podría aplicar las retenciones por pagos al exterior reguladas en los Artículos del 406 al 411 ET.

Al mismo tiempo, se resaltaría que este colombiano no residente tiene un contrato laboral en Colombia, situación que lo convierte en un asalariado. Por lo tanto, también se podría configurar la retención en la fuente consagrada en el Artículo 383 del ET. A pesar de que este artículo trata sobre retenciones por pagos laborales a personas naturales clasificadas en la categoría de empleados, y de que el sujeto que se analiza en este estudio no clasifica en esa categoría por el hecho de no ser residente, el Decreto 099 de 2013 Artículo 1 en el parágrafo 1 contempla la posibilidad de aplicar la retención en la fuente del Artículo 383 a aquellas personas naturales que no clasifican en la categoría tributaria de empleados, pero que tienen una relación laboral legal y reglamentaria. Teniendo en cuenta lo anterior, se estaría frente a una antinomia del Artículo 383 del ET, frente al Artículo 408 del ET inciso uno, provocada por el parágrafo 1 Artículo 1 del Decreto 099.

Teniendo en cuenta la modificación que el Artículo 17 de la Ley 1819 de 2016 hace al Artículo 383 del ET, se observa que esta modificación elimina la figura de empleado para esta retención en la fuente, al derogar el parágrafo 1 del Artículo 1 del Decreto 099 de 2013, debido a que los asalariados ya no necesitan clasificar como empleados para poder aplicar la retención del Artículo 383 del ET. En el marco de las observaciones anteriores, a los colombianos asalariados no 
residentes se les puede aplicar la retención contemplada en el Artículo 383 del ET, y en ese mismo sentido también se les puede aplicar dicha retención a los extranjeros asalariados no residentes, en el entendido de que la nueva versión de la retención del Artículo 383 del ET no tiene en cuenta los requisitos de nacionalidad ni de residencia para aplicar y descontar dicha retención a las personas naturales.

El problema jurídico es el siguiente: Para resolver la antinomia descrita en el apartado anterior, se tendrían dos puntos de vista: antes y después de la reforma tributaria Ley 1819 de 2016. Sin embargo, la solución no es fácil, porque de acuerdo con la realidad fáctica descrita, se contraponen varias reglas de solución de antinomias, las cuales se describen a continuación.

Antes de la reforma tributaria Ley 1819 de 2016 se contraponen dos reglas. La primera es la de ley especial, que conlleva a la aplicación del Artículo 408 del ET, por ser un no residente; y la segunda es la presunción de legalidad, que permite la aplicación del Decreto 099 de 2013, el cual conlleva la aplicación del Artículo 383 del ET, por tener un contrato laboral.

Después de la reforma tributaria Ley 1819 de 2016, para resolver la cuestión también hay dos reglas que se contraponen. Por un lado, el criterio de ley especial lleva a la aplicación del Artículo 408 del ET, por ser un no residente; y por el otro lado, opera la regla de ley posterior, que lleva a aplicar el renovado Artículo 383 del ET (modificado por la Ley 1819 de 2016), por obtener una renta de trabajo contemplada en el Artículo 103 del ET.
De la misma manera que el colombiano asalariado no residente tendría dos conceptos de retención en la fuente, al extranjero asalariado no residente también se le estarían configurando dos conceptos de retención en la fuente. Por un lado, el de los Artículos 407 a 411 del ET, por ser extranjero no residente; y por el otro, sería el contemplado en el Artículo 383 del ET, por ser un asalariado bajo las normas colombianas.

Sobre la base de las consideraciones anteriores, es importante determinar cuál sería el escenario de la doble retención, si este trabajador ingresara al territorio nacional bajo la protección de la ley de trabajador migratorio: Ley 146 de 1994. En consecuencia, a continuación, se presentan las conclusiones del estudio sobre el impacto de esta norma en los no residentes colombianos.

\section{Trabajador migratorio}

Ante todo, se toma en cuenta que el sujeto objeto de estudio tiene las siguientes características:
$\checkmark$ Asalariado (contrato docente y contra- tación diferente a docente);
$\checkmark$ de nacionalidad colombiana;
$\checkmark$ no es residente fiscal en Colombia.

Resulta oportuno hacer una relación de este colombiano no residente con la Ley 146 de 1994, la cual protege a los trabajadores migrantes que provienen de un país cobijado por la Convención de Nueva York.

Además, hay que tener en cuenta que Colombia se encuentra en un proceso de querer repatriar a todos los colombianos que se fueron a otro país. 


\section{A. Trabajador colombiano no residente}

Para el caso objeto de estudio, se trata de un docente de nacionalidad colombiana, el cual tiene su domicilio en Venezuela, pero viene a Colombia todos los años a desarrollar un contrato laboral como docente en una universidad del Caribe colombiano.

En los marcos de las observaciones anteriores, a este colombiano no residente se le tendría que dar el tratamiento en tarifa de renta de acuerdo con lo siguiente:

$\checkmark$ Por el contrato docente, la tarifa debiera ser del $7 \%$, contemplada en el Artículo 409 del ET, pero por no ser extranjero, no le aplica.

$\checkmark$ Por el contrato diferente a docente, el 33\% del Artículo 247 del ET, y por ser de nacionalidad colombiana, no podría solicitar la protección de la Convención de Nueva York al trabajador migrante. Esto, a pesar de no ser residente y provenir de un país que ha firmado dicha convención.

\section{B. Trabajador extranjero no residente}

La Convención de Nueva York sobre la protección del trabajador migrante fue aprobada en Colombia por la Ley 146 de 1994. En esta última, se define al trabajador migrante como una persona natural de nacionalidad extranjera, la cual viene a Colombia a desarrollar un contrato laboral. Por consiguiente, el trato que se le debe dar es el mismo que a un nacional colombiano. No obstante, hay que tener en cuenta que debe ser en condiciones análogas, es decir, a las de un nacional sin residencia.
Lo anterior trae como consecuencia el siguiente problema jurídico. En el marco de la ley de protección del trabajador migrante, se puede observar una situación de inequidad de los colombianos migrantes cuando vienen de otros países, frente a los extranjeros que asimismo provienen de otro país. Esto en el sentido de que a los colombianos migrantes no se les puede aplicar la Ley 146 de 1994, por el hecho de no ser extranjeros.

Los extranjeros no residentes, como ya se ha aclarado, están protegidos por la ley de trabajador migrante. Significa entonces que se les debe dar el mismo tratamiento tributario que a los nacionales en situaciones análogas. Es decir, que les apliquen las tarifas del Artículo 383 como si se tratara de un nacional residente. No obstante, y según la doctrina construida por la Dian, este extranjero no residente, primero tiene que cumplir con la residencia, para poder aplicarle la tarifa del Artículo 383 del ET.

Como consecuencia de esto, no tendría ninguna razón de ser solicitar la protección del trabajador migrante, porque a cualquier trabajador que venga de otro país a trabajar a Colombia, provenga o no de un país firmante de la Convención de Nueva York, le aplicarían la tarifa contemplada en el Artículo 247 del ET.

\section{Sistema de declaración}

El tratamiento tributario, en materia de tarifa de retención en la fuente, impuesto sobre la renta y obligación formal de declarar, no es el único problema que deben enfrentar los colombianos no residentes cuando vienen a laborar a su país. En esta sección se abordará el sistema de declaración al que 
los colombianos no residentes se tienen que someter, en el evento en que cumplan con las condiciones para ser declarantes por el periodo gravable.

Antes de la reforma tributaria Ley 1819 de 2016. Dadas las condiciones existentes para los sistemas de declaración de las personas naturales antes de la reforma Ley 1819 de 2016, se puede afirmar que el docente (y también asalariado) colombiano no residente no podría aplicar los sistemas de declaración de empleado y trabajador por cuenta propia (IMAN e IMAS), dado que el Artículo 329 del ET reserva este sistema para los residentes, colombianos o extranjeros, únicamente.

Con referencia a lo anterior, el docente colombiano no residente, por los ingresos recibidos en el contrato laboral obtenidos en Colombia, tendría que declararlos por el sistema ordinario, formulario 210, sin liquidar IMAN, y hacer la depuración con las condiciones de ingresos, costos, deducciones y rentas exentas de los asalariados. De esta manera, obtendrá la renta líquida gravable, a la cual le deberá aplicar la tarifa del Artículo 247 del ET.

Después de la reforma tributaria Ley 1819 de 2016. Cuando entra en vigencia la reforma tributaria en mención, las condiciones del docente (y asalariado) colombiano no residente con respecto a su sistema de declaración siguen iguales, al tener que declarar los ingresos obtenidos en una relación laboral en Colombia por el sistema ordinario. Esto, en el sentido de que la Ley 1819 de 2016 elimina las figuras de empleado y trabajador por cuenta propia, y en su reemplazo establece un nuevo sistema de declaración bajo el método de renta cedular, pero vuelve a condicionar este nuevo método sólo para los residentes colombianos. Sin embargo, hasta el momento, se puede observar que el docente colombiano no residente no tendría formulario de declaración de renta, debido a que el formulario 210 está dividido por las diferentes cédulas, según la Resolución DiAN 045 de 2017. A su vez, el formulario 110 está diseñado para las personas jurídicas y las personas naturales obligadas a llevar contabilidad. Por lo anterior, se considera que deben diseñar un nuevo formulario o modificar los actuales para que el docente colombiano no residente pueda declarar renta por el sistema ordinario, según el Artículo 26 del ET.

El problema jurídico sería que el docente colombiano sin residencia en el país, a pesar de estar laborando en una universidad colombiana con las condiciones dadas en el Artículo 409 del ET, no puede acogerse a la tarifa del $7 \%$ contemplada en el citado artículo, por el solo hecho de ser un docente colombiano, debido a que la retención está reservada para los docentes extranjeros.

Para terminar este tema, se destaca este importante punto: después de la reforma tributaria Ley 1819 de 2016, el Legislador mantuvo -en el Artículo 10- la misma posición de dar esta tarifa especial del 7\% solo a los docentes extranjeros. Por lo tanto, aplicaría la regla de ley posterior frente a los argumentos que la Dian plantea en el Concepto 24300 de 21 de agosto de 2015 y el Oficio 016385 de 2015, de entenderse eliminada tácitamente la palabra extranjero de los Artículos 406, 409 y 592 de ET. Lo que quiere decir que se mantiene la figura de docente extranjero, lo cual deja sin fundamento 
los argumentos de la Dian en los conceptos antes citados.

\section{Una mirada a los Convenios para Evitar la Doble Imposición (CDI)}

A continuación, se presentan las conclusiones del análisis de los 10 convenios para evitar la doble imposición (en adelante, CDI) vigentes y aceptados por Colombia con los siguientes países: España, Francia, Canadá, Corea, India, México, Portugal, República Checa, Suiza y Chile. En dichos convenios se puede observar una cláusula de no discriminación, la cual aparece en el Artículo 23 de cada convenio, con excepción de uno de los convenios -el firmado con Chile-, que la contempla en el Artículo 24.

Se tienen en cuenta los convenios citados en el párrafo anterior, y que además el sujeto objeto de estudio de este trabajo de investigación reúne las siguientes características: es una persona natural de nacionalidad colombiana, no residente en Colombia, residente fiscal en Venezuela y contratado por una universidad colombiana como docente. También, se ha analizado con contratos laborales diferentes al de docente, es decir, como un asalariado.

De acuerdo con las consideraciones anteriores, hay que tener en cuenta que Colombia no tiene firmado CDI con Venezuela, pero para analizar los efectos que estos generan en los sujetos objetos del presente estudio, se analizaron los CDI vigentes a la fecha de elaboración de este trabajo de investigación.

Para analizar la cláusula de no discriminación y los efectos que ocasiona en el sujeto objeto de estudio, se debe remitir al primer inciso de los Artículos 23 y 24 de cada CDI. Hay que tener en cuenta que no todos los incisos son iguales; por lo tanto, se analizarán en primer lugar los CDI con Francia, Canadá y Chile. A continuación, se trae a colación: "Los nacionales de un Estado contratante no estarán sometidos en el otro Estado contratante a ningún impuesto ni obligación relativa al mismo que no se exijan o que sean más gravosos que aquellos a los que estén o puedan estar sometidos los nacionales de ese otro Estado que se encuentren en las mismas condiciones, en particular con respecto a la residencia”.

Con referencia al inciso anterior, se puede observar que la cláusula de no discriminación busca mitigar que los efectos impositivos de los extranjeros en un Estado contratante no sean más gravosos que los de los nacionales del otro Estado contratante en iguales condiciones, y esas condiciones las define la residencia. Por lo tanto, la cláusula de no discriminación contemplada en estos convenios no le aplica al sujeto bajo estudio, en el entendido de que este es una persona natural de nacionalidad colombiana y dicha cláusula le aplica a los nacionales del otro Estado contratante; es decir, a los extranjeros que se encuentren en Colombia.

Por otro lado, la cláusula de no discriminación es similar a lo contemplado en la Convención de Nueva York sobre la protección del trabajador migrante, con la diferencia que en los CDI quedó escrito que las condiciones en ambos Estados deben ser las mismas, pero que dichas condiciones deben estar enmarcadas por el factor residencia.

Sin embargo, en los CDI vigentes con España, Corea, India, México, Portugal, Re- 
pública Checa y Suiza se incorpora al inciso primero de la cláusula de no discriminación lo siguiente: "No obstante lo dispuesto en el Artículo 1, la presente disposición se aplicará también a las personas que no sean residentes de uno o de ninguno de los Estados contratantes". Ello deja la posibilidad de que los no residentes de algunos de los Estados contratantes se beneficien de las cláusulas del convenio, tal como lo dice (Lang, 2014, pág. 79): "Conforme a un sector de la doctrina, las reglas de no-discriminación normalmente incluidas en los CDI pueden conducir a que personas que no son residentes del estado contratante accedan a los beneficios del convenio".

Para el caso específico de los profesores, solo tres convenios contemplan esa figura: India, Corea y Francia.

Con respecto al CDI firmado entre Colombia y los países de India y Corea, se puede observar que en el Artículo 20 de dichos convenios se trata el tema específico de los profesores y docente. Por consiguiente, si un docente visita a un Estado contratante y realiza labores de enseñanza e investigación, no estará sujeto a impuestos en ese Estado por dos (2) años, siempre y cuando haya sido residente del otro Estado contratante en el año de la visita o el inmediatamente anterior. De acuerdo con esto, se observa que la nacionalidad del docente no afecta las condiciones que se tienen en cuenta para aplicar el beneficio que otorga el convenio.

Para el caso del docente objeto de estudio, esta cláusula le favorecería, debido a que Venezuela sería el otro estado contratante y es donde posee la residencia fiscal. Ello, sin importar que no tenga la nacionalidad venezolana, porque la cláusula no tiene en cuenta ese elemento.

En el caso particular de Francia, con respecto a los profesores, lo que se puede resaltar es la mejor forma en que el beneficio de esta cláusula quedó redactado; es decir, que se puede observar que el docente, en el Estado de la residencia, puede ser sometido a tributación. Además, para el método de calcular el tiempo de uso del beneficio, utiliza el término de 24 meses y no de los 2 años. Por otro lado, y a diferencia de los convenios con India y Corea, la cláusula para el docente es incorporada en el numeral 3 del Artículo 14 del convenio, el cual se refiere a las rentas de trabajo dependientes.

Con referencia al Artículo 14 de los convenios, sobre rentas de trabajo dependiente, este puede servir para analizar los efectos de los CDI en el sujeto estudiado, sobre todo en los contratos diferentes al de docente.

Sobre la base de las consideraciones anteriores, si un colombiano no residente fiscal en Colombia celebra un contrato laboral con una empresa nacional pero no como docente, estaría entonces bajo la figura de un asalariado normal. Por lo tanto, si se analiza a la luz de los convenios, este clasificaría bajo la cláusula de "rentas de trabajo dependiente", debido a que los contratos laborales en Colombia tienen una relación de subordinación y no existe para el asalariado riesgo empresarial, tal como lo afirma Michael Lang:

El Artículo 15 del modelo OCDE regula lo referente a las rentas de trabajo dependiente. Este concepto no se encuentra definido en el Artículo 15 del modelo OCDE. Sin embargo, su contenido puede deducirse de la 
distinción existente entre la renta del trabajo dependiente y los beneficios empresariales del Artículo 7 del modelo OCDE o las rentas de trabajo independiente del antiguo Artículo 14 del modelo OCDE, respectivamente. La relación de subordinación y la falta de riesgos empresariales tienen su papel (Lang, 2014, p. 135).

En el mismo orden de ideas, la potestad tributaria quedaría como lo dice Lang, (2014, p. 136): "el Artículo 15 del modelo OCDE atribuye la potestad tributaria exclusiva al estado de residencia del perceptor." Sin embargo, ese mismo autor afirma que en el Estado de la actividad también se puede tener potestad tributaria, si se llegara a incumplir con alguno de los siguientes requisitos:

$\checkmark$ El perceptor de la renta permanece en el otro Estado durante un periodo que no exceda de 183 días;

$\checkmark$ la remuneración es pagada en nombre de un empleador que no es residente del otro Estado;

$\checkmark$ la remuneración no es soportada por un EP que el empleador tenga en el otro Estado.

Es evidente, entonces, que en el presente estudio de casos la potestad tributaria la tiene Colombia, en el sentido de que la remuneración está a cargo de un empleador que es residente en el país.

Finalmente, se resalta que, independiente de las regulaciones internas de cada país, se puede entender que los CDI buscan equilibrar las potestades tributarias que tiene cada Estado cuando se presenta doble tributación por razones de la fuente y la residencia. Así lo hace saber José Manuel Castro cuando afirma que:

Los CDI contienen un régimen fiscal para las distribuciones internacionales de beneficios que entran en su ámbito de aplicación, que se superpone sobre el ya asignado por los Estados de la fuente y la residencia, pudiendo potenciar o reducir las asimetrías en la calificación y las faltas de neutralidad en su imposición, según el mejor o peor diseño que adopte cada tratado (Castro Arango, 2016, p. 75).

\section{El impacto del problema destacado a lo largo del Estatuto Tributario, una reforma inacabada}

\section{A. Revisión de la palabra extranjero a lo largo del Estatuto Tributario}

En esta sección se presentan los resultados de un rastreo de la palabra extranjero por todo el ET, con el objetivo de determinar las implicaciones que tiene en el mismo el hecho de haber eliminado dicha palabra únicamente en el Artículo 247 del mencionado estatuto. De acuerdo con los razonamientos que se han venido realizando, no queda clara la hipótesis de la DIAN al afirmar que la palabra extranjero se entiende eliminada tácitamente de los Artículos 406 y numeral 2 del Artículo 592 del ET, por el simple hecho de que la reforma tributaria Ley 1819 de 2016 eliminó del Artículo 247 del ET la palabra extranjero.

Para efectos del rastreo, se buscó la palabra extranjero en los artículos donde afecta a las personas naturales. Vale aclarar que no se tuvieron en cuenta las afectaciones 
de dicha palabra en las personas jurídicas y asimiladas a estas.

La metodología que se usó en esta sección para desarrollar las reflexiones finales se hizo como se describe a continuación: primero, se realizó una transcripción del artículo tal como está redactado en el ET. Luego, se resaltó la palabra extranjero. Y, finalmente, en un párrafo siguiente, se hicieron los comentarios pertinentes.

A continuación, se relacionan los artículos del ET que afectaron a las personas naturales por la palabra extranjero. Además, para esos artículos, se plantea una propuesta de solución, para decidir si esa palabra en cada artículo se deroga o sencillamente si se modifica o no.

Artículo 9. Impuesto de las personas naturales, residentes y no residentes.

Artículo 123. Requisitos para su procedencia.

Artículo 247. Tarifa del impuesto de renta para personas naturales sin residencia (en 1 parágrafo).

Artículo 261. Patrimonio bruto.

Artículo 292-2. Impuesto a la riqueza - sujetos pasivos (numerales 2 y 3 ).

Artículo 295-2. Base gravable (numeral 8).

Artículo 316. Para personas naturales extranjeras sin residencia (artículo modificado por el Artículo 108 de la Ley 1607 de 2012).

Artículo 389. Cuáles están sometidos a retención.

Artículo 401-2. Retención en la fuente en indemnizaciones.

Artículo 406. Casos en que debe efectuarse la retención (numerales 1, 2 y 5).
Artículo 409. Tarifa especial para profesores extranjeros.

Artículo 412. Tarifa sobre los contratos "llave en mano" y demás contratos de confección de obra material.

Artículo 592. Quiénes no están obligados a declarar (numeral 2).

\section{B. Una propuesta de solución}

De acuerdo con la problemática desarrollada en este trabajo de investigación sobre los colombianos no residentes, para dar una propuesta de solución se tendría que adoptar una de las siguientes posiciones:

$\checkmark$ Posición 1: existen supuestos mal o no regulados en el ET en lo referente a los colombianos no residentes.

$\checkmark$ Posición 2: podría acudirse a una interpretación sistemática a partir de la reforma 1607 de 2012, en donde podría entenderse que cuando el ET menciona a los extranjeros se refiere a residentes personas naturales.

$\checkmark$ Posición 3: Que exista una derogatoria tácita en todo el ET cuando se refiere a las personas naturales extranjeras.

Teniendo en cuenta los argumentos desarrollados en esta investigación, para dar una propuesta de solución se adopta la Posición 1. En consecuencia, a continuación, se ofrecerán los argumentos por los cuales no se eligieron las otras dos posiciones.

$\checkmark$ Posición 2: no se puede adoptar esta posición debido a que hay artículos en el ET que deben seguir conservando la distinción sobre los extranjeros y los colombianos, como en el caso de los siguientes: 9, 261, 292, 314 y 316. Ade- 
más, las interpretaciones sistemáticas versan sobre el mismo tema, tal como lo afirma Arnau Moya (2009, p. 55): "la interpretación sistemática relaciona la norma de que se trata con las que integran la misma institución jurídica, y cada institución con las demás hasta llegar a los principios fundamentales del sistema". Por lo tanto, no se puede hacer una interpretación sistemática porque la palabra extranjero, cuando se utiliza en los citados artículos, tiene una finalidad distinta a la prevista en la palabra extranjero derogada por la Ley 1607 de 2012 en el Artículo 247 del ET.

$\checkmark$ Posición 3: al igual que en el punto anterior, no se puede entender derogada en el ET la palabra extranjero, debido a que hay algunos artículos que necesitan tal distinción.

A su vez, las razones fundamentales que conllevaron a tomar la posición 1 fueron: que el legislador no ha desarrollado una reforma tributaria de forma estructural, que modifique en todo el ET las diferencias entre los nacionales y extranjeros, los residentes y no residentes; que conlleven por fin a un giro en el sistema tributario de las personas naturales, determinado para los residentes y no residentes, para de esta forma acabar con las discriminaciones que existen con los colombianos no residentes.

Por lo anterior, y teniendo en cuenta las consideraciones de la revisión de la palabra extranjero en todo el ET, lo que se debe hacer para solucionar el problema planteado es lo siguiente:

$\checkmark$ Que el MHCP no emita para 2017 el decreto para definir los no declarantes para este mismo año gravable, debido a que existe normativa en el ET sobre ese tema, tales como los Artículos del 592 hasta el 594-3.

$\checkmark$ Solicitar la anulación de los decretos que el MHCP emitió por los años 2013 hasta el 2016, donde determina los no obligados a declarar por esos años gravables.

$\checkmark$ Finalmente, proponer un proyecto de ley que contenga las siguientes modificaciones al Estatuto Tributario:

- Modificar la redacción de los siguientes artículos para eliminar la palabra extranjero: Artículo 123, el parágrafo del 247, el inciso primero de los Artículos 389 y $401-2$, los numerales 2 y 3 del 406, el Artículo 409, y el numeral 2 del Artículo 592.

- Derogar el numeral 8 del Artículo 295-2.

- Por último, en el Artículo 412, eliminar la siguiente frase: "personas naturales sin residencia y las sucesiones de causantes extranjeros sin residencia", y reemplazarla por esta otra: "personas naturales y asimiladas sin residencia".

\section{Referencias}

Arnau Moya, F. (2009). Lecciones de Derecho Civil. Castelló de la Plana: Universidad Jaime I servei de comunicació.

Bravo Arteaga, J. R. (2000). Nociones fundamentales de Derecho Tributario. Bogotá: Legis.

Castro Arango, J. (2016). El concepto de dividendo en los convenios de doble imposicion. Bogotá: Universidad Externado de Colombia.

Congreso de la República de Colombia (1989). Estatuto Tributario. Bogotá, Colombia.

Congreso de la República de Colombia (diciembre de 2016). Ley 1819 de 2016. Bogotá. 
Congreso de la República de Colombia (1887). Código Civil Ley 57 de 1887. Bogotá.

Congreso de la República de Colombia (diciembre de 2012). Ley 1607 de 2012. Bogotá.

Congreso de la República de Colombia (diciembre de 2014). Ley 1732 diciembre de 2014. Bogotá.

Congreso de la República de Colombia (13 de julio de Ley 146 de 1994). Ley 146 de 1994. Ley de trabajadores migratorios. Bogotá.

Corredor Alejo, J. O. (2010). Ajuste de Derecho Tributario Colombiano. Bogotá: Hache.

Consejo de Estado, Sala de consulta y Servicio Civil (18 de junio de 2014). Derogatoria tácita, potestad reglamentaria, 2143

DIAN Concepto 007254 de marzo 9 de 2015. Bogotá.

DIAN (30 de marzo de 2007). Concepto 025242.

DIAN (30 de septiembre de 2015). Concepto 028448. Bogotá.

DIAN (21 de agosto de 2015). Concepto 24300. Bogotá.

DIAN (2016). Oficio 010479. Bogotá.

DIAN (03 junio de 2015). Oficio 016385. Bogotá.

Gascón Abellán, M. (2008). «Cuestiones sobre la derogación», en U. Schmill Ordóñez, Observaciones $a$ «Inconstitucionalidad y derogación» (pp. 79 a 119). Alicante: Doxa - Filosofía del Derecho.

Gutiérrez Argüello, M. S. (2015). «Algunos conflictos de la regla de residencia y del régimen de tributación de las personas naturales», en G. F. Medina, 39 Jornadas de Derecho Tributario, Derecho Aduanero y Derecho Exterior (pp. 777 a 804). Bogota: Instituto Colombiano de Derecho Tributario.

Hoyos Londoño, V. y Rodríguez Peña, C. C. (2015). «Retención en la fuente por pagos laborales», en J. R. Piza Rodríguez, P. E. Sarmiento Perezy R. Insignares Gómez, El impuesto sobre la renta y complementarios Consideraciones teóricas y prácticas (p. 808). Bogotá: Universidad Externado de Colombia.

Idrovo Cubides, J. M. (2015). «Personas naturales y residencia en el marco de la tributación internacional», en G. F. Medina, 39 Jornadas de Derecho Tributario,
Derecho Aduanero y Comercio Exterior (pp. 757 a 776). Bogotá: Instituto Colombiano de Derecho Tributario.

Jaramillo, C.A. (1997). La redacción del texto jurídico. Bogotá: Editorial Linotipia Bolívar y Cía. S. en C.

Lang, M. (2014). Introducción al Derecho de los convenios para evitar la doble imposición. Bogotá: Temis.

Larenz, K. (1994). Metodología de la Ciencia del Derecho. Barcelona: Ariel S.A.

León Campos, C. V. (2015). «El concepto de residencia en materia de tributación directa», en J. R. Piza Rodríguez, P. Sarmiento Pérez y R. Insignares Gómez, El impuesto sobre la renta y complementarios: Consideraciones teóricas y páacticas (p. 808). Bogotá: Universidad Externado de Colombia.

Llanes A., A. A. (2017). «Retención por pagos al exterior: modificaciones de la Ley 1819 a los Artículos 408, 410, 414-1 y 415 del Estatuto Tributario», en J. R. Piza Rodríguez, Análisis crítico sobre la Reforma Tributaria. Ley 1819 de 2016 (p. 800). Bogotá: Universidad Externado de Colombia.

Milton, C. G. (2017). Cómo interpretar las normas tributarias. Bogotá.

Muñoz Martínez, G., y Zornoza Pérez, J. J. (2015). «La aplicación de las normas tributarias», en J. R. Piza Rodríguez, La obligación tributaria y sus fundamentos constitucionales (p.471). Bogotá: Universidad Externado de Colombia.

Navarro, M. W. (2015). Problemas jurídicos de los expatriados en Colombia. (Tesis de maestría). Universidad Externado de Colombia, Bogotá.

Sabogal Guevara, R. A. ( 2014). «Aproximación crítica al régimen tributario de las personas naturales establecido en la Ley 1607 de 2012», en G. FigueredoMedina, Memorias de las 38 Jornadas Colombianas de Derecho Tributario (pp. 13 a 76). Bogotá: Instituto Colombiano de Derecho Tributario.

Zornoza Pérez, J. J. y Muñoz Martínez, G. (2007). «La aplicación de las normas fiscales», en J. R. Piza, R. Insignares Gómez, M. Marín Elizalde, G. Muñoz Martínez yJ. J. Zornoza Pérez, Curso de Derecho fiscal (p. 741). Bogotá: Universidad Externado. 